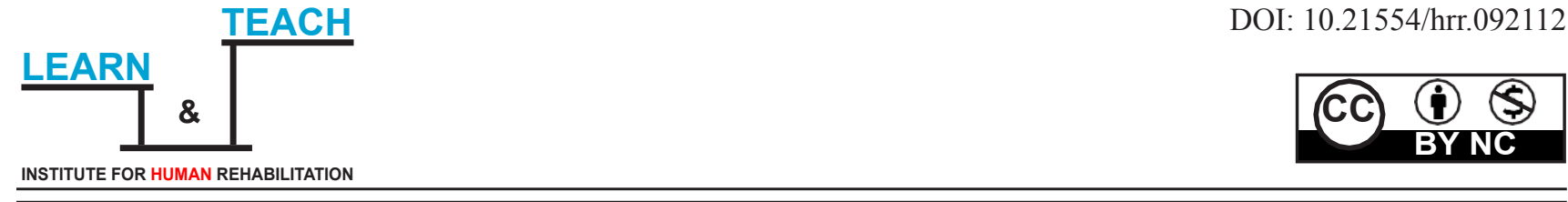

\title{
DIFFERENCES BETWEEN DEAF AND HARD OF HEARING STUDENTS IN MOTIVATION FOR ACADEMIC ACHIEVEMENT
}

Original scientific paper

\author{
Meliha Povlakic Hadziefendic ${ }^{1}$, Esad H. Mahmutovic ${ }^{2}$ \\ ${ }^{I}$ Center for Hearing and Speech Rehabilitation, Sarajevo, Bosnia and Herzegovina \\ ${ }^{2}$ Center for Education and Rehabilitation of DHH Students, Tuzla, Bosnia and Herzegovina
}

Received: 2021/3/12

Accepted: 2021/6/18

\begin{abstract}
Goal of this paper was to determine differences between deaf and hard of hearing (DHH) students in motivation for academic achievement and compared to hearing students. Sample was comprised of 94 students averaging $16.5 \pm 1.34$ years of age. Sample was divided into three groups (deaf, hard of hearing and hearing students). For examination, we used the following: Great Inventory of Achievement Motivation, measuring instrument for assessing students' motivation for academic achievement, that is comprised of five subtests i.e. 13 areas of measurement (Suzic, 2006). For difference testing $t$-test was used along with analysis of variance (ANOVA). T-test determined statistically significant difference in areas of "self-efficacy ", "engagement", "control" and "non-conformism". Deaf and hard of hearing students displayed less motivation on these parameters than their hearing counterparts. In the area of "valuing academic achievements" DHH students together displayed, better motivation than their hearing counterparts and difference was statistically significant. With Analysis of Variance i.e. with additional Tukey test, we have determined that statistically significant difference is present only when comparing deaf and hearing students, but not when comparing hard of hearing and hearing students. Keywords: deaf and hard of hearing, students, motivation, academic achievement
\end{abstract}

\section{INTRODUCTION}

In order to achieve their goals, needs and instincts, human beings acquire the sufficient motivation. Particularly with respect to students, motivation for academic achievement is of great importance. By such motivation people are stimulated to successfully complete an assignment, achieving a goal or a degree of qualification in their professions (Mohamadi, 2006; see to Amrai et al., 2011).

In order for student to be engaged in certain curriculum, it is important that they know why they are studying. Motive is needed for them to start acting to achieve certain goal. Lack of interest for school obligations is an indicator that student is not motivated and they do not understand what is the reason behind studying. In recent time, literature has shown that learning outcomes, academic achievement and academic performance could be determined by such variables as: family, school, society, and motivation (Aremu \& Oluwole,2001; Ozcinar, 2006; see Rahmani, 2011). „Most contemporary theories of motivation assume that people initiate and persist at behaviors to the extent that they believe the behaviors will lead to desired outcomes or goals" (Deci \& Ryan, 2000, p. 227). Understanding the phenomenon of what energized and direct an individual to develop interest, enjoyment, and persistence for learning as opposed to boredom and disengagement is central to learning motivation research (Ryan \& Deci, 2000; see Garn, Matthews, \& Jolly, 2010).

Lack of motivation can manifest itself because of doubt in personal abilities. If a student assesses that they will be unsuccessful in learning and understanding contents

\footnotetext{
Correspodence to:

Meliha Povlakic Hadziefendic, Center for Hearing and Speech Rehabilitation, Sarajevo, Bosnia and Herzegovina

Asima Ferhatovica 2, Sarajevo 71000, Bosnia and Herzegovina

Phone:+387 61635290

E-mail: melihapovlakicotmail.com
} 
of the curriculum, that it is too hard for them, that they will not achieve any results, then they will not even start learning. If the feeling inadequacy repeats itself, it begins to make a person believe that they are an inadequate person and hence they will make no goals that would propel them towards academic achievement. Competence is the ability of making necessary regulations and organizations for reaching the person's goal, and having the perception of self confidence for accomplishing them. Personal competence is achievement, the others' success, the person's belief of his own success and his psychological state. Competence is formed by the individual's learning, adaptation and interaction with environment. Insofar as the person has that perception, it is more likely to be successful (Deci \& Ryan, 1985; Carver \& Scheier, 1990; Garcia \& Pintrich, 2009; see Ummet, 2015). If real tasks are posed to a student, either by teachers or parents, it can affect development their sense of competency. If that is not the case, student can experience failure, and negative feedback could cause drop in motivation for further efforts.

"When it comes to deaf and hard of hearing students, they approach classroom obligations and learning with varying interest. They display different forms of behaviour and are persistent to a greater or lesser extent in performing their school obligations. These children set different goals when it comes to their academic achievement. These differences in involvement and engagement indicate the existence of different motives that drive them to action as well as different forms of motivation that sustain their action" (Mahmutovic \& Povlakic Hadziefendic, 2020, p. 47).

Considering specific development of deaf and hard of hearing children, among other things, it is important to know predictors that affect academic achievements of these students.

Apart from the obvious effects of the degree, type and quality of instruction, five variables appear to be closely correlated with the academic achievement of students with hearing impairment (Moores, 1985, Paul \& Quigley, 1990; see Ogundiran i Olaosun, 2013): 1. The severity of hearing impairment - The greater the hearing loss, the more likely the child will experience difficulty in learning language and academic skills. 2. The age of onset of hearing loss - A child who loses his hearing before acquiring speech and language (usually before age 2) is at a much greater disadvantage than a child with a post lingual hearing impairment. 3. Intelligence test scores - As with children with normal hearing, higher scores on standardized tests of intelligence are correlated with greater amounts of academic success. 4. Socio-economic status of the family - A child with hearing impairment whose parents are affluent and college educated is more likely to achieve academic success than a child with hearing impairment from a low-income and less educated family. 5. The hearing status of the parents - A child with deafness from parents with deafness is considered to have better chances for academic success than a deaf child born by hearing parents, particularly if the parents are highly educated.
Stinson and Kluwin (2003; see Richardson, Marschark, Sarchet, \& Sapere, 2010) reviewed the literature with regard to academic placement for DHH students and concluded that the largest contribution to academic achievement came from differences in student and family characteristics (e.g., age of hearing loss onset, prior academic achievement, and parental hearing status).

Psychological needs are interconnected and dependent upon each other. If DHH student has support from their family - that will fulfil their need for human connection. If they have support from teachers - that will develop sense of autonomy in their studies. Sense of freedom in choosing topics and contents, that are interesting to them, will develop students' sense of competence. Fulfillment of these psychological needs, will affect development of positive attitude towards the school and therefore the development of intrinsic motivation and by result better academic achievement. If DHH student has their basic psychological needs met, their self-respect will also grow.

Joiner, Erickson, and Crittenden (1966; see Moores \& Martin, 2006), for example, found that deaf students in a residential high school with relatively high selfesteem tended to have high grade-point averages. „Students with deafness should be taught to understand that the outcomes of achievement related behaviors are self-produced (Internal locus of control). They should be trained to become self driven in achieving goals, academic and otherwise" (Ogundiran \& Olaosun, 2013, p. 46).

Besides development of competencies and fulfillment of psychological needs of DHH students, and for the reason of conducting adequate educational process when it comes to motivation for academic achievements, special attention needs to be directed towards degree of loss of hearing and differences in motivation levels between DHH students in comparison to their hearing counterparts.

Degree of hearing loss does not appear to be a direct predictor of academic achievement (Allen, 1986; Powers, 2006; Tymms, Brien, Merrell, Collins, \& Jones, 2003). Nevertheless, it does affect access to communication within the classroom and has more subtle long-term effects insofar as cognitive skills, world knowledge, and fluency in language are acquired through an incremental and interactive process extending over many years (Richardson, et al.., 2010, p. 359). „It is assumed that due to the lack of auditory modality there is certain psychological restructuring in relation to the communication models, which in turns affects the development of cognitive functions, due to which deaf people differ significantly from hearing people in terms of psychological characteristics" (Hasanbegovic \& Sinanovic, 2008).

"The motivation of deaf and hard of hearing students may be affected by poor auditory perception, which leads to difficulties in understanding and mastering certain classroom contents, which in turns diminishes the interest in a certain area and the student fails to make an effort to master the material. 
If a student's attention has been attracted to a particular material, by means of easy to understand and appropriately introduced content, he/she will understand the purpose of learning, which will in turn arouse his/her interest and thereby his/her persistence in performing activities related to the task" (Mahmutovic \& Povlakic Hadziefendic, 2020, p. 49).

Goal of this paper was to determine differences between deaf and hard of hearing (DHH) students in motivation for academic achievement and compared to hearing students.

\section{METHODS}

\section{The sample}

Sample was comprised of 94 students (46 males and 48 females), with age averaging $16.5 \pm 1.34$ years. For the needs of the research, sample was divided into 3 groups. First group was comprised of deaf students (30 student), with hearing loss over $90 \mathrm{~dB}$. Second group was comprised of hard of hearing students (17 students), with hearing loss between 70 and $90 \mathrm{~dB}$. Third control group was comprised of hearing students, chosen randomly, from three regular elementary and high schools. Age of hearing students was matched with their deaf or hard of hearing counterparts.

\section{Measuring instrument}

GIAM - Great Inventory of Achievement Motivation (Suzic, 2006) is measuring instrument used for assessing academic achievement motivation of students. It is comprised of five subtests:

1. self-efficacy and competence;

2. attribution and belief about ability to control;

3. students' interest for curriculum and perception of competence;

4. evaluation level of academic achievement;

5. goals.

Instrument measured 13 areas with total of 128 items (claims) that were used to examine attitudes of students towards motivation for school achievements. Respondents were expressing their opinions in form of agreeing or disagreeing with given claims (yes or no answers). It is self-expression that has attributive character. During calibration, Cronbach alpha coefficient ( $\alpha=.93)$ indicated very good reliability of general score of instruments for this sample.

\section{Data analysis}

Distributive analysis was conducted on collected data, i.e. calculation of mean with corresponding standard deviations. For testing differences between DHH students and hearing students t-test was used for independent samples. For results comparisons for three groups of students (deaf, hard of hearing and hearing) analysis of variance (ANOVA) was used. Differences testing was determined on $5 \%$ accuracy level (.05). Data was processed in SPSS program (version 17) for Windows.

\section{RESULTS AND DISCUSSION}

\section{Differences between students with hearing loss (DHH) and hearing students in motivation for academic achievement}

In Table1, assessment results of differences between DHH students and hearing students in motivation for academic achievement. T-test for independent samples, has shown some differences between these two groups of students, in all assessed areas except the "performative self-efficacy". However, statistically significant difference was observed for four areas in which DHH students displayed less motivation than their hearing counterparts.

These areas are:

1. "Self-efficacy" $(\mathrm{t}=-2.30 ; \mathrm{p}=.00)-$ Area was assessed by following claims:

- For studying and success in school, I can get support and praise any time I want.

- I am capable to comprehend and master the material in each subject if I really want to.

- I can receive praise and support for studying and effort from my peers in school.

- I am capable to use all books, computers and other means for studying.

- When there is conflict between my peers I try to reconcile them and I can easily resolve the conflict.

- I can help least interested, weakest and most "difficult" student to master the materials.

- I am capable to organize and finish my tasks and studies even when tasks are unexpected and difficult.

- I am capable to handle all problems that I encounter in life.

- I can win trust and respect from my peers.

- I can win trust and respect from my teachers.

2. "Engagement" $(\mathrm{t}=-2.16, \mathrm{p}=.03)$ - Area was assessed by following claims:

- I am sad when I finish reading good book because it feels like parting with a good friend.

- I like to read science fiction and stuff that make me think.

- I like curriculum material that makes me think.

- While I study I create images in my mind.

- I enjoy watching long action movies and stories or books with mystery theme.

- I like when teacher demands interactivity from us.

- I like to work on group presentations and to present what my group did.

3. "Control" $(\mathrm{t}=-2.19, \mathrm{p}=.00)-$ Area was assessed by claims:

- When I am about to start studying, I am asking myself how to master the material and what to do if I could not do it.

- I usually find quiet place where I will study and work on the materials.

- When doing homework, I usually use dictionary, lecture notes and books.

- When studying for test, I try to connect what I previously learned with what I am currently learning. 
- When I hear something new during the lecture I try to connect it to what I have already learned before.

- In order to understand the material, I utilize questions such as: why, what and how.

- I always try to find a way for material to be interesting and fun for me. I like to know as soon as possible if I have mastered material or successfully passed the test.

4. "Non-conformism" $(\mathrm{t}=-2.75, \mathrm{p}=.01)$ - Area assessed with following claims:

- I learn what the teacher say I should learn

- I always write homework because the teacher asks that from me.

- During the lectures I ask questions in order to be noticed.

- When I don't understand something I immediately raise my hand and ask for explanation.

- I like when teacher help me when I am working on the curriculum materials

- When teacher gives unfair grade to someone I rebel against it.

- I like for a teacher to plan what I am going to learn.

- I can protect myself from "tough" teachers.

- When I know something that isn't being taught in school, I ask for permission to speak about it or demonstrate it.

- I don't like peers that constantly complain to the teacher.

In the area of "Evaluation of academic achievements" DHH students displayed better motivation than their hearing counterparts $(\mathrm{t}=3.05$, $\mathrm{p}=.00)$ and difference was statistically significant. This area was assessed by following claims:

- I go to school to be able to study for vocation I want later on.
- To become what I want.

- I go to school because I will learn there something that I would not be able to without the school.

- I go to school because there are subjects that I am especially interested in.

- Years in school will enhance my general capabilities.

- One who doesn't attend school will be weaker than the one who does.

- If there would be a pill or candy that contained all math knowledge in the world, there would be no child that would refuse it.

- In school, I can learn things I am interested in.

- One would go crazy if they were to study everything.

When observing contents of the claims that describe perception of students in isolated areas, results seem logical and informationally significant, taking into account that we're observing two essentially different groups of respondents in terms of hearing status and therefore different educational process.

Considering obtained results, we can conclude that it is important to improve self-efficacy of DHH students in order to improve their motivation levels. This can be achieved through engagement and control which are areas that are reduced due to speech-language limitations caused by hearing loss. These areas should be worked on, based on objective capabilities of every individual. Results in the area of valuing academic achievements by DHH students, show that these students are expecting a lot from their education, even more than their hearing counterparts. Because of this, it is important that expectations are used by everyone in an educational process so results are as best as possible.

Table 1. T-test difference between DHH students and hearing students in motivation for academic achievements

\begin{tabular}{|c|c|c|c|c|c|c|}
\hline \multirow{2}{*}{ Motivation component } & \multicolumn{2}{|c|}{ DHH students } & \multicolumn{2}{|c|}{ Hearing students } & \multirow{2}{*}{$t$} & \multirow{2}{*}{$p$} \\
\hline & M & SD & M & SD & & \\
\hline Self-efficacy & 6.28 & 2.72 & 7.77 & 2.05 & -2.30 & .00 \\
\hline Performative Self-efficacy & 6.26 & 3.31 & 6.26 & 2.81 & .00 & 1.00 \\
\hline Perception of competence & 4.47 & .97 & 4.17 & 1.22 & 1.31 & .19 \\
\hline Self-value & 9.19 & 5.07 & 10.83 & 3.50 & -1.82 & .07 \\
\hline Self-determination & 6.34 & 1.89 & 6.15 & 1.55 & .54 & .59 \\
\hline Engagement & 4.00 & 2.34 & 4.91 & 1.72 & -2.16 & .03 \\
\hline Challenge & 3.66 & 2.71 & 4.53 & 2.00 & -1.78 & .08 \\
\hline Control & 4.85 & 2.39 & 5.81 & 1.83 & -2.19 & .03 \\
\hline Interest in curriculum & 5.81 & 2.54 & 6.06 & 1.95 & -.55 & .59 \\
\hline Valuing academic achievement & 7.89 & 1.59 & 6.70 & 2.16 & 3.05 & .00 \\
\hline Mastery & 7.34 & 2.05 & 7.23 & 2.31 & .24 & .81 \\
\hline Performance goals & 6.02 & 2.67 & 5.64 & 2.75 & .69 & .50 \\
\hline Non-conformism & 3.83 & 1.55 & 4.62 & 1.21 & -2.75 & .01 \\
\hline
\end{tabular}


Differences between deaf, hard of hearing and hearing students in motivation for academic achievement

In order to come to more precise conclusions, in terms of motivation of DHH students for academic achieves, differences between three groups of respondents have been examined.
Those groups are deaf, hard of hearing and hearing students. Results analysis of ariance have shown that there are statistically significant differences for areas of "self-efficacy" $(\mathrm{F}=5.2 ; \mathrm{p}=.01)$, "engagement" $(\mathrm{F}$ $=3.73 ; \mathrm{p}=.03)$, "valuing academic achievement" $(\mathrm{F}$ $=4.66 ; \mathrm{p}=.01)$ and "non-conformism" $(\mathrm{F}=6.96 ; \mathrm{p}=$ .00) (Table 2).

Table 2. ANOVA, surveying students on GIAM

\begin{tabular}{|c|c|c|c|c|c|}
\hline Motivation component & Students & Mean & SD & $\mathbf{F}$ & $p$ \\
\hline \multirow{4}{*}{ Self-efficacy } & Deaf & 5.97 & 2.70 & & \\
\hline & Hard of hearing & 6.83 & 2.77 & & \\
\hline & Hearing & 7.77 & 2.05 & & \\
\hline & Total & 7.02 & 2.51 & 5.20 & .01 \\
\hline \multirow{4}{*}{ Performative Self-efficacy } & Deaf & 5.83 & 3.60 & & \\
\hline & Hard of hearing & 7.00 & 2.67 & & \\
\hline & Hearing & 6.26 & 2.81 & & \\
\hline & Total & 6.26 & 3.05 & .79 & .46 \\
\hline \multirow{4}{*}{ Perception of competence } & Deaf & 4.40 & .81 & & \\
\hline & Hard of hearing & 4.59 & 1.23 & & \\
\hline & Hearing & 4.17 & 1.22 & & \\
\hline & Total & 4.32 & 1.11 & 1.00 & .37 \\
\hline \multirow{4}{*}{ Self-value } & Deaf & 8.90 & 5.28 & & \\
\hline & Hard of hearing & 9.71 & 4.79 & & \\
\hline & Hearing & 10.83 & 3.50 & & \\
\hline & Total & 10.01 & 4.41 & 1.84 & .17 \\
\hline \multirow{4}{*}{ Self-determination } & Deaf & 6.03 & 1.94 & & \\
\hline & Hard of hearing & 6.88 & 1.73 & & \\
\hline & Hearing & 6.15 & 1.55 & & \\
\hline & Total & 6.24 & 1.72 & 148 & .23 \\
\hline \multirow{4}{*}{ Engagement } & Deaf & 3.63 & 2.40 & & \\
\hline & Hard of hearing & 4.65 & 2.15 & & \\
\hline & Hearing & 4.91 & 1.72 & & \\
\hline & Total & 4.46 & 2.09 & 3.73 & .03 \\
\hline \multirow{4}{*}{ Challenge } & Deaf & 3.50 & 2.80 & & \\
\hline & Hard of hearing & 3.94 & 2.61 & & \\
\hline & Hearing & 4.53 & 2.00 & & \\
\hline & Total & 4.10 & 2.41 & 1.75 & .18 \\
\hline \multirow{4}{*}{ Control } & Deaf & 4.67 & 2.52 & & \\
\hline & Hard of hearing & 5.18 & 2.16 & & \\
\hline & Hearing & 5.81 & 1.83 & & \\
\hline & Total & 5.33 & 2.17 & 2.69 & .07 \\
\hline \multirow{4}{*}{ Interest in curriculum } & Deaf & 5.93 & 2.57 & & \\
\hline & Hard of hearing & 5.59 & 2.55 & & \\
\hline & Hearing & 6.06 & 1.95 & & \\
\hline & Total & 5.94 & 2.26 & .27 & .76 \\
\hline \multirow{4}{*}{ Valuing academic achievement } & Deaf & 7.97 & 1.40 & & \\
\hline & Hard of hearing & 7.76 & 1.92 & & \\
\hline & Hearing & 6.70 & 2.16 & & \\
\hline & Total & 7.30 & 1.98 & 4.66 & .01 \\
\hline
\end{tabular}


Table 2. Continued

\begin{tabular}{|c|c|c|c|c|c|}
\hline Motivation component & Students & Mean & SD & $\mathbf{F}$ & $p$ \\
\hline \multirow{4}{*}{ Mastery } & Deaf & 7.03 & 2.13 & & \\
\hline & Hard of hearing & 7.88 & 1.83 & & \\
\hline & Hearing & 7.23 & 2.31 & & \\
\hline & Total & 7.29 & 2.17 & .85 & .43 \\
\hline \multirow{4}{*}{ Performance goals } & Deaf & 6.47 & 2.74 & & \\
\hline & Hard of hearing & 5.24 & 2.41 & & \\
\hline & Hearing & 5.64 & 2.76 & & \\
\hline & Total & 5.83 & 2.70 & 1.37 & .26 \\
\hline \multirow{4}{*}{ Non-conformism } & Deaf & 3.47 & 1.31 & & \\
\hline & Hard of hearing & 4.47 & 1.77 & & \\
\hline & Hearing & 4.62 & 1.21 & & \\
\hline & Total & 4.22 & 1.44 & 6.96 & .00 \\
\hline
\end{tabular}

These results, in the same areas, confirm determined differences between two groups - students with hearing loss $(\mathrm{DHH})$ and hearing students. In areas where statistically significant difference between groups was observed, we have conducted comparisons between groups via additional Tukey HSD test. Statistically significant difference between deaf and hearing students was observed in all four areas, as well as between deaf and hard of hearing students in area of non-conformism.
Consequences that are a result of hearing loss, such as communication problems, then, methods and conditions (integration and segregation) in educational system, all contribute to these attitudes in different ways and in relation to assessing areas which indicate level of motivation. That is confirmed by results that show no significant differences in any observed area, between hard of hearing students, who are included in regular education, and their hearing peers (Table 3 ).

Table 3. Multiple Comparisons - Tukey HSD test

\begin{tabular}{|c|c|c|c|c|}
\hline Motivation component & Students (I) & Students $(\mathrm{J})$ & $\begin{array}{c}\text { Mean Difference } \\
\text { (I-J) }\end{array}$ & $p$ \\
\hline \multirow{6}{*}{ Self-efficacy } & \multirow{2}{*}{ Deaf } & Hard of hearing & -.86 & .47 \\
\hline & & Hearing & $-1.80(*)$ & .01 \\
\hline & \multirow[t]{2}{*}{ Hard of hearing } & Deaf & .86 & .47 \\
\hline & & Hearing & -.94 & .35 \\
\hline & \multirow[t]{2}{*}{ Hearing } & Deaf & $1.80(*)$ & .01 \\
\hline & & Hard of hearing & .94 & .35 \\
\hline \multirow{6}{*}{ Engagement } & \multirow[t]{2}{*}{ Deaf } & Hard of hearing & -1.01 & .23 \\
\hline & & Hearing & $-1.28(*)$ & .02 \\
\hline & \multirow[t]{2}{*}{ Hard of hearing } & Deaf & 1.01 & .23 \\
\hline & & Hearing & -.27 & .89 \\
\hline & \multirow[t]{2}{*}{ Hearing } & Deaf & $1.28(*)$ & .02 \\
\hline & & Hard of hearing & .27 & .89 \\
\hline \multirow{6}{*}{ Valuing academic achievement } & \multirow[t]{2}{*}{ Deaf } & Hard of hearing & .20 & .94 \\
\hline & & Hearing & $1.26(*)$ & .02 \\
\hline & \multirow[t]{2}{*}{ Hard of hearing } & Deaf & -.20 & .94 \\
\hline & & Hearing & 1.06 & .13 \\
\hline & \multirow[t]{2}{*}{ Hearing } & Deaf & $-1.26(*)$ & .02 \\
\hline & & Hard of hearing & -1.06 & .13 \\
\hline \multirow{6}{*}{ Non-conformism } & \multirow[t]{2}{*}{ Deaf } & Hard of hearing & $-1.00(*)$ & .04 \\
\hline & & Hearing & $-1.15(*)$ & .00 \\
\hline & \multirow[t]{2}{*}{ Hard of hearing } & Deaf & $1.00(*)$ & .04 \\
\hline & & Hearing & -.15 & .92 \\
\hline & \multirow[t]{2}{*}{ Hearing } & Deaf & $1.15\left(^{*}\right)$ & .00 \\
\hline & & Hard of hearing & .15 & .92 \\
\hline
\end{tabular}


Researches that included academically successful deaf persons indicates the importance of motivation for academic achievement in hearing impaired students.

Luckner and Muir's study sought to understand the attributes of 20 academically successful mainstreamed students who were deaf. The study also included interview data from 19 parents, 19 general education teachers, and 13 teachers of the deaf. The parents in this study reported that their children did not want to be treated differently than their peers with typical hearing. These students also sought recognition for scholarly efforts (e.g., awards, certificates, and high grades). The educators further observed that the students had a sense of belonging among peers with typical hearing and lacked social inhibition regarding their deafness. These students further demonstrated selfadvocacy skills and a strong internal drive to be independent. (Luckner \& Muir, 2001; see Jacobs, 2010).

In order to better understand academic achievement among deaf and hard-of-hearing students in different educational placements, an exploratory study examined the experiences of postsecondary students enrolled in mainstream programs (with hearing students) versus separate programs (without hearing students) at the same institution. Both groups were concerned with good teaching and the acquisition of generic skills. Both were motivated by the demands of their assessments and by a fear of failure while being alert to both positive and negative affect in their classroom interactions. Overall, students in separate classes were more positive about workload expectations, instructor feedback, and the choices they had in coursework. Students in mainstream classes were more positive about their acquisition of analytic skills (rather than rote memorization) and about their instructors' interest in them, including flexibility in methods of assessment. (Richardson et al, 2010).

Bain et al.'s (2004) study featured 38 non-signing adults who were deaf and who were highly educated, socially connected, and professionally successful. The majority of participants had developed psychosocial strategies to negotiate social difficulties related to deafness, including the Desire to educate others about deafness and adapt to the needs of others by participating in activities and maintaining a lifestyle similar to peers with typical hearing. Participants also expressed selfconfidence, little social anxiety, and pride in their strategic adaptive skills. Additional findings related to desire included the participants' motivation to improve speech-reading skills, to enunciate speech more clearly, and to initiate modifications in their environment to ensure ease of communication. (Bain et al., 2004; see Jacobs, 2010).

Toscano, McKee, and Lepoutre (2002; see Marschark, Convertino, \& LaRock, 2006) found that deaf college students who demonstrated high academic literacy skills tended to have parents who were very involved in their early educations, effective family communication (regardless of mode), early and intensive exposure to reading and writing, and high expectations on the part of their parents.
„Parental support, appropriate educational style and parent involvement, degree of support and control are positive factors in the development of self-esteem, social skills development and competence, motivation and school achievement" (Povlakic Hadziefendic, Mahmutovic, \& Hasanbegovic, 2019, p. 83).

Many participants in Reiff et al.'s (1995) study reported that anger originating from incidents in childhood, particularly anger toward the school system, was a catalyst for what would later become successful professional and social outcomes. Other participants maintained their Desire into adulthood through rewards gained from particular endeavors, encouragement from significant others (e.g., family and teachers), or understanding that basic academic survival required sustained determination. Many participants also appeared determined to prove the stereotypes of their disability wrong (e.g., low expectations imposed by others) and that these external influences would not decide their fate (Jacobs, 2010, p. 11).

\section{CONCLUSION}

Based on this research, we can observe that there are statistically significant differences when it comes to motivation for academic achievements in deaf, hard of hearing and hearing students. Biggest differences were observed in areas of self-efficiency, engagement and control. We can conclude that self-efficiency should be improved via areas of engagement and control. Better self-efficiency means better motivation and that dismisses results obtained for area of valuing academic achievement, where DHH students have shown bigger expectations from education in comparison to expectations of hearing students. Positive evaluation of self-efficiency, competency and self-determination factors in deaf students indicates high self-respect, better interest for curriculum, active engagement and setting goals for the future which results in good academic achievements. While academic achievement is considered one of most important indicators of studying, all participants in the education of a child (parents, teachers and others) should be involved as much as possible in improving aforementioned factors.

\section{REFERENCES}

Amrai, K., Motlagh, S. E., Zalani, H. A., \& Parhon, H. (2011). The relationship between academic motivation and academic achievement students. Procedia-Social and Behavioral Sciences, 15, 399-402. DOI: 10.1016/j.sbspro.2011.03.111

Deci, E. L., \& Ryan, R. M. (2000). The" what" and" why" of goal pursuits: Human needs and the self-determination of behavior. Psychological inquiry, 11(4), 227-268. Retrieved from http://users.ugent.be/ wbeyers/scripties2011/ artikels/Deci\&Ryan_2000.pdf

Garn,A.C., Matthews, M. S., \& Jolly, J. L. (2010). Parental influences on the academic motivation of gifted students: A selfdetermination theory perspective. Gifted Child Quarterly, 54(4), 263-272. DOI: 10.1177/0016986210377657

Hasanbegovic, H., \& Sinanovic, O. (2008). Procjena određenih psiholoških karakteristika kod gluhih osoba [Estimate of certain psychic characteristics at tested deaf people]. Acta Medica Saliniana, 37(2), 127-131. 
Jacobs, P. (2010). Psychosocial potential maximisation: A framework of proactive psychosocial attributes and tactics used by individuals who are deaf. The Volta Revie, 110(1), 5-29.

Mahmutovic \& Povlakic Hadziefendic M. (2020). Developing the motivation of deaf and hard of hearing students to learn and academic achievement. Human Research in Rehabilitation, 10(2) 46-52. DOI: 10.21554/hrr.092005

Marschark, M., Convertino, C., \& LaRock, D. (2006). Optimizing academic performance of deaf students: Access, opportunities, and outcomes. In Moores, F. D. i Martin S. D. (Eds.). Deaf learners: New developments in curriculum and instruction (pp. 179-200). Washington, D.C. 20002: Gallaudet University Press

Moores, F. D, \& Martin, S. D. (2006). Overview: Curriculum and Instruction 3 in General Education and in Education of Deaf Learners. In Moores, F. D. i Martin S. D. (Eds.). Deaf Learners. Developments in Curriculum and Instruction (pp. 3-15). Washington, D.C. 20002: Gallaudet University Press

Ogundiran, O., i Olaosun, A.O. (2013). Comparison of Academic Achievement between Students with Congenital and
Acquired Deafness in a Nigerian College. Journal of Education and Practice, 4 (23), 42-48. Preuzeto sa http:// www.iiste.org/Journals/index.php/JEP/article/view/8387

Povlakic Hadziefendic, M., Mahmutovic, E.H., \& Hasanbegovic, H. (2019). Perception of parental support by deaf and hardof-hearing students. Human Research in rehabilitation, 9(1):82-87.

Rahmani, P. (2011). The relationship between self-esteem, achievement goals and academic achievement among the primary school students. Procedia-Social and Behavioral Sciences, 29, 803-808. doi:10.1016/j.sbspro.2011.11.308

Richardson, J. T., Marschark, M., Sarchet, T., \& Sapere, P. (2010). Deaf and Hard-of-Hearing Students' Experiences in Mainstream and Separate Postsecondary Education. Journal of deaf studies and deaf education, 15(4), 358-382. doi:10.1093/deafed/enq030

Suzic, N. (2006) Mjerenje motivacije. Naša škola - časopis za teoriju i praksu vaspitanja i obrazovanja, 3-4: 88-121

Ummet, D. (2015). Self esteem among college students: a study of satisfaction of basic psychological needs and some variables. Procedia-Social and Behavioral Sciences, 174, 1623-1629. doi: 10.1016/j.sbspro.2015.01.813 